\title{
XXXII. Account of a series of experiments, showing the effects of compression in modifying the action of heat
}

\section{Sir James Hall Bart. F.R.S.}

To cite this article: Sir James Hall Bart. F.R.S. (1806) XXXII. Account of a series of experiments, showing the effects of compression in modifying the action of heat, Philosophical Magazine Series 1, 25:99, 193-215, DOI: 10.1080/14786440608563435

To link to this article: http://dx.doi.org/10.1080/14786440608563435

曲 Published online: 18 May 2009.

Submit your article to this journal $\pi$

Џll Article views: 2

Q View related articles $\sqsubset$ 


\section{$\left[\begin{array}{ll}193 & ]\end{array}\right.$}

XXXII. Account of a Series of Experiments, showing the Effects of Compression in modifying the Action of Heat. By Sir JAMES HALL, Bart. F.R.S. Lond. and Edin.

[Concluded from p. 157.]

\section{\$IX.}

Application of the foregoing Results to Geology.-The Fire employed in the Huttonian Theory is a Modification of that of the Volcanoes.-This Modification must take place in a Lava previous to its Eruption.-An internal Lava is capable of melting Limestone.-The Effects of Volcanic Fire on Sulstances in a subterranean and sul-marine Situation, are the same as those ascribed to Fire in the Huttonian Theory.-Our Strata were once in a similar Situation, and then underwent the Action of Fire.-All the Conditions of the Huttonian Theory being thus combined, the Formation of all Rocks may be accounted for in a satisfactory Manner.-Conclusion.

$\mathrm{H}$ Aving investigated, by means of the foregoing experiments, some of the chemical suppositions involved in the Huttonian theory, and having endeavoured to assign a determinate limit to the power of the agents employed, I shall now apply these results to geology, and inquire how far the events, supposed antiently to have taken place, accord with the existing state of our globe.

The most powerful and essential agent of the Huttonian theory is fire, which I have always looked upon as the same with that of volcanoes, modified by circumstances which must, to a certain degree, take place in every lava previous to its eruption.

The original source of internal fire is involved in great obscurity; and no sufficient reason occurs to me for deciding whether it proceeds by emanation from some vast central reservoir, or is generated by the local operation of some chemical process. Nor is there any necessity for such a decision; all we need to know is, that internal fire exists, which no one can doubt, who believes in the eruptions of Mount

Vol. 25. No. 99. Aug. 1806. N

Vesuvius, 
Vesuvius. To require that a man should account for the generation of internal fire, before he is allowed to employ it in geology, is no less absurd than it would be to prevent him from reasoning about the construction of a telescope, till he could explain the nature of the sun, or account for the generation of light*. But wbile we remain in suspense as to the prime cause of this tremendous agent, many circumstances of importance with regard to it may fairly become the subjects of observation and discussion.

Some authors (I conceive through ignorance of the facts) have alleged, that the fire of Etna and Vesuvius is merely superficial. Büt the depth of its action is sufficiently proved by the great distance to which the cruptive percussions are felt, and still more by the substances thrown out uninjured by some eruptions of Mount Vesuvius. Some of these, as marble and gypsum, are incapable, in freedom, of resisting the action of fire. We have likewise granite, schistus, gneiss, and stones of every known class, besides many which have never, on any other occasion, been found at the surface of our globe. The circumstance of these substances having been thrown out unaffected by the fire, proves that it has proceeded from a source, not only as deep, but deeper than their native beds; and as they exhibit specimens of every class of minerals, the formation of which we pretend to explain, we need inquire no further into the depth of the Vesuvian fire, which bas thus been proved to reach below the range of our speculations.

Volcanic fire is subject to perpetual and irregular variations of intensity, and to sudden and violent renewal, after long periods of absolute cessation. These variations and intermissions are likewise essential attributes of fire, as employed by Dr. Hutton; for some geological scenes prove that the indurating cause has acted repeatedly on the same substance, and that, during the intervals of that action, it had ceased entirely. This circumstance affords a complete

* This topic, however, has of 1 ate been much urged against us, and an unfair advantage has been taken of what Mr. Playfair has said upon it. What he gave as mere conjecture on a subject of collateral importance, has been argued upon as the basis and fundameutal doctrine of the system.

answer 
answer to an argument lately urged against the Huttonian theory, founded on the waste of heat which must have taken place, as it is alleged, through the surface. For if, after absolute cessation, a power of renewal exists in nature, the idea of waste by continuance is quite inapplicable.

The external phænomena of volcanoes are sufficiently well known; but our subject lcads us to inquire into their internal actions. This we are enabled to do by means of the foregoing experiments, in so far as the carbonate of lime is concerned.

Some experiments, which I formerly * laid before this society and the public, combined with those mentioned in this paper, prote that the feeblest exertions of volcanic fire are of sufficient intensity to perform the agglutination, and even the entire fusion, of the carbonate of lime, when its carbonic acid is effectually confined by pressure; for though lava, after its fusion, may be made, in our experiments, to congeal into a glass in a temperature of $16^{\circ}$ or $18^{\circ}$ of Wedgewood, in which temperature the carbonate would scarcely be affected, it must be observed that a similar congelation is not to be looked for in nature; for the mass, even of the smallest stream of lava, is too great to admit of such rapid cooling. And, in fact, the external part of a lava is not vitreous, but consists of a substance which, as my experiments have proved, must have been congealed in a heat of melting silver, that is, in $22^{\circ}$ of Wedgewood; while its internal parts bear a character indicating that they congealed in $27^{\circ}$ or $28^{\circ}$ of the same scale. It follows, that no part of the lava, while it remained liquid, can have been less hot than $22^{\circ}$ of Wedgewood. Now, this happens to be a heat in which I have accomplished the entire fusion of the carbonate of lime under pressure. We must therefore comclude, that the heat of a running lava is always of sufficient intensity to perform the fusion of limestone.

In every active volcano a communication must exist between the summit of the mountain and the unexplored region, far below its base, where the lava has been melted,

* Edinburgh Tratsactions, vol. v. part i. p. 60-66. 
and whence it has been propelled upwards; the liquid lava rising through this internal channel, so as to fill the crater to the brim, and flow over it. On this occasion, the sides of the mounlain must undergo a violent hydrostatical pressure outwards, to which they often yield by the formation of a vast rent, through which the lava is discharged in a lateral eruption, and flows in a continued stream sometimes during months. On Etna most of the eruptions are so performed; few lavas flowing fron the summit, but generally breaking out laterally at very clevated stations. At the place of delivery, a quantity of gaseous matter is propelled violently upwards, and, along with it, some liquid lava; which last, falling back again in a spongy state, produces one of those conical hills which we see in great number on the vast sides of Mount Etua, each indicating the discharge of a particular eruption. At the same time, a jet of flame and smoke issues from the main crater, proving the internal communication between it and the lava; this discharge from the summit generally continuing, in a greater or a less degree, during the intervals between eruptions. (Fig. 41. represents an ideal section of Mount Ftna; $a b$ is the direct channel, and $l c$ is a lateral branch).

Let us now attend to the state of the lava within the mountain during the course of the eruption; and let us suppose, that a fragment of limestone, torn from some stratum below, has been included in the fluid lava, and carried up with it. By the laws of hydrostatics, as each portion of this fluid sustains pressure in proportion to its perpendicular distance below the point of discharge, that pressure must increase with the depth. The specific gravity of solid and compact lava is nearly $2 \cdot 8$; and its weight, when in a liquid state, is probably little different. The table shows that the carbonic acid of limestone cannot be constrained in beat by a pressure less than that of 1708 feet of sea, which corresponds nearly to 600 feet of liquid lava. As soon, then, as our calcareous mass rose to within 600 feet of the surface, its carbonic acid would quit the lime, and, assuming a gaseous form, would ard to the eruptive effervescence. And this change would commonly begin in much greater depths, 
in consequence of the bubbles of carbonic acid, and other substances, in a gaseous form, which, rising with the lava, and through it, would greatly diminish the weight of the column, and would render its pressure on any particular spot extremely variable. With all these irregularities, however, and interruptions, the pressure would in all cáses, especially where the depth was considerable, far surpass what it would have been under an equal depth of water. IWhere the depth of the stream, below its point of delivery, amounted, then, to 1708 feet, the pressure, if the heat was not of excessive intensity, would be more than sufficient to constrain the carbonic acid, and our limestone would suffer no calcination, but would enter into fusion; and if the eruption ceased at that moment, would crystallize in cooling along with the lava, and become a nodule of calcareous spar. The mass of lava containing this nodule would then constitute a real whinstone, and would belong to the kind called amygdaloid. In greater depths still, the pressure would be proportionally increased, till sulphur, and even water, might be constrained ; and the carbonate of lime would continue undecomposed in the highest heats.

If, while the lava was in a liquid state, during the eruption or previous to it, a new rent (de, fig. 41.), formed in the solid country below the volcano, was met by our stream (at $d$ ), it is obvious that the lava would flow into the aperture with great rapidity, and fill it to the minutest extremity, there being no air to impede the progress of the liquid. In this manner, a stream of lava might be led from below to approach the bottom of the sea $(f f)$, and to come in contact with a bed of loose shells $(g g)$ lying on that bottom, but covered with beds of clay, interstratified, as usually occurs, with beds of sand, and other beds of shells. The first effect of heat would be to drive off the moisture of the lowest shell-bed in a state of vapour, which, rising till it got beyond the reach of the heat, would be condensed into water, producing a slight motion of ebullition, like that of a vessel of water, when it begins to boil, and when it is said to simmer. The beds of clay and sand might thus undergo some heaving and partial derangement, but would still possess the 
power of stopping, or of very much impeding, the descent of water from the sea above; so that the water which had been driven from the shells at the bottom would not return to them, or would return but slowly; and they would be exposed dry to the action of heat*.

In this case; one of two things would inevitably happen: either the carbonic acid of the shells would be driven off by the heat, producing an incondensable elastic fluid, which, heaving up or penetrating the superincumbent beds, would force its way to the surface of the sea, and produce a submarine eruption, as has happened at Santorini and elsewhere, or the volatility of the carbonic acid would be repressed by the weight of the superincumbent water $(k k)$, and the shell-bed, being softened or fused by the action of heat, would be converted into a stratum of limestone.

The foregoing experiments enable us to decide in any particular case, which of these two events must take place when the heat of the lava and the depth of the sea are known.

The table shows, that under a sea no deeper than 1708 feet, near one-third of a mile, a limestone would be formed by proper heat; and that, in a depth of little more than one mile, it would enter into entire fusion. Now, the common soundings of mariners extend to 200 fathoms, or 1200 feet. Lord Mulyrave + found bottom at 4680 feet, or nearly ninetenths of a mile; and captain Ellis let down a sea-gage to the depth of 5346 feet + . It thus appears, that at the bottom of a sea which would be sounded by a line much less than double of the usual length, and less than half the depth of that sounded by lord Mulgrave, limestone might be formed by heat; and that at the depth reached by captain Ellis, the entire fusion would be accomplished, if the bed of shells were touched by a lava at the extremity of its course, when its heat was lowest. Were the heat of the lava greater, a

* This situation of things is similar to what happens when small-coal is moistened, in order to make it cake. The dust, drenched with water, is laid upon the fire, and remains long wet, while the heat below suffers little or no abatement.

+ Voyage towards the North Pole, p. 149.

$\neq$ Philosophical Trausactions 1751 , p. 212 . 
greater depth of sea would, of course, be requisite to constrain the carbonic acid effectually; and future experiments may determine what depth is required to co-operate with any given temperature. It is enough for our present purpose to have shown that the result is possible in any case, and to have circumscribed the necessary force of these ayents within moderate limits. At the same time it must be observed that we have been far from stretching the known facts; for, when we compare the small extent of sea in which any soundings can be found, with that of the vast unfathomed ocean, it is obvious, that in assuming a depth of one mile or two, we fall very short of the medium. M. de la Place, reasoning from the phænomena of the tides, states it as highly probable that this medium is not less than eleven English miles*.

If a great part or the whole of the superincumbent mass consisted, not of water, but of sand or clay, then the depth requisite to produce these effects would be lessened in the inverse ratio of the specific gravity. If the above-mentioned occurrence took place under a mass composed of stone firmly bound together by some previous operation of nature, the power of the superincumbent mass, in opposing the escape of carbonic acid, would be very much increased by that union and by the stiffness or tenacity of the substance. We have seen numberless examples of this power in the course of these experiments, in which barrels, both of iron and porcelain, whose thickness did not exceed one-fourth of an inch, have exerted a force superior to the mere weight of a mile of sea. Without supposing that the substance of a rock could in any case act with the same advantage as that of an uniform and connected barrel, it seems obvious that a similar power must, in many cases, have been exerted to a certain degree.

We know of many calcareous masses which, at this moment, are exposed to a pressure more than sufficient to ac-

* "On peut donc regarder au moins comme très probable, que la profondeur moyenne de la mer n'est pas au-dessous de quatre lieues."-De la Place, Hist. de l'Acad. Roy. des Sciences, année 1776.

N 4 complish 
complish their entire fusion. The mountain of Saleve, near Geneva, is 500 French fathoms, or nearly 3250 English feet, in height, from its base to its summit. Its mass consists of beds, lying nearly horizontal, of limestone filled with shells. Independently, then, of the tenacity of the mass, and taking into account its mere weight, the lowest bed of this mountain must, at this moment, sustain a pressure of 3250 feet of limestone, the specific gravity of which is about 2.65. This pressure, therefore, is equal to that of 8612 feet of water, being nearly a mile and a half of sea, which is much more than adequate, as we have shown, to accomplish the entire fusion of the carbonate on the application of proper heat. Now, were an emanation from a volcano to rise up under Saleve, and to penetrate upwards to its base, and stop there, the limestone to which the lava approached would inevitably be softened without being calcined, and, as the heat retired, would crystallize into a saline marble.

Some other circumstancer relating to this subject are very deserving of notice, and enable us still further to compare the antient and modern operations of fire.

It appears, at first sight, that a lava, having once penetrated the side of a mountain, all subsequent lavas should continue, as water would infallibly do, to flow through the same aperture. But there is a material difference in the two cases. As soon as the lava has ceased to flow, and the heat has begun to abate, the crevice through which the lava bad been passing remains filled with a substance, which soon agglutinates into a mass far harder and firmer than the mountain itself. This mass, lying in a crooked bed, and being firmly welded to the sides of the crevice, must oppose a most powerful resistance to any stream tending to pursue the same course. The injury done to the mountain by the formation of the rent, will thus be nuch more than repaired, and in a subsequent eruption the lava must force its way through another part of the mountain or througb some part of the adjoining country. The action of heat from below seems in most cases to have kept a channel open through the axis of the mountain, as appears by the smoke and flame which is habitually discharged at the summit during inter- 
vals of calm. On many occasions, however, this spiracle seems to have been entirely closed by the consolidation of the lava, so as to suppress all emission. This happened to Vesuvius during the middle ages. All appearance of fire had ceased for five hundred years, and the crater was covered with a forest of aritient oaks, when the volcano opened with fresh vigour in the sixteenth century.

The eruptive force capable of overcoming such an obstacle must be tremendous indeed, and seems in some cases to have blown the volcano itself almost to pieces. It is impossible to see the mountain of Somma, which, in the form of a crescent, embraces Mount Vesuvius, without being convinced that it is a fragment of a large volcano, nearly concentric with the present inner cone, which, in some great eruption, had been destroyed all but this fragment. In our own times, an event of no small magnitude has taken place on the same spot; the inner cone of Vesuvius having undergone so great a change during the eruption in 1794, that it now bears no resemblance to what it was when I saw it in 1785 .

The general or partial stagnation of the internal lavas at the close of each eruption seems, then, to render it necessary, that in every new discharge the lava should begin by making a violent laceration. And this is probably the cause of those tremendous earthquakes which precede all great eruptions, and which cease as soon as the lava has found a vent. It seems but reasonable to ascribe like effects to like causes, and to believe that the earthquakes which frequently desolate countries not externally volcanic, likewise indicate the protrusion from below of matter in liquid fusion penetrating the mass of rock.

The injection of a whinstone-dike into a frail mass of shale and sandstone, must have produced the same effects mpon it that the lava has just been stated to produce on the loose beds of volcanic scoria. One stream of liquid whin, having flowed into such an assemblage, must have given it great additional weight and strength; so that a second stream, coming like the first, would be opposed by a mass the laceration of which would produce an earthquake if it were over- 
come, or by which, if it resisted, the liquid matter would be compelled to penetrate some wcaker mass, perhaps at a great distance from the first. The internal fire, being thus compelled perpetually to change the scene of its action, its influence might be carried to an indefinite extent; so that the intermittence in point of time, as well as the versatility in point of place, already remarked as common to the Huttonian and volcanic fires, are accounted for on our principles: and it thus appears that whinstone possesses all the properties which we are led by theory to ascribe to an internal lava.

This connection is curiously illustrated by an intermediate case between'the results of external and internal fire, displayed in an actual scction of the antient part of Vesuvius, which occurs in the mountain of Somma, mentioned above. I formerly described this, scene in my paper on whinstone and lava; and I must beg leave once more to press it upon the notice of the public, as affording to future travellers a most interesting field of geological inquiry.

The section is seen in the bare vertical cliff several hundred feet in height, which Somma.presents to the view from the little valley, in form of a crescent, which lies between Somma and the interior cone of Vesuvius, called the Atrio del Cavallo. (Fig. 42. represents this scene, done from the recollection of what I saw in $1785 . a b c$ is the interior cone of Vesuvius; $d f g$ the mountain of Somma; and $c d e$ the Atrio del Cavallo). By mean's of this cliff ( $f d$ in fig. 42 , and which is repreşented separately in fig. 44), we see the internal structure of the mountain, composed of thick beds $(k k)$ of loose scoria which have fallen in showers, between which thin but firm streams $(\mathrm{mm})$ of lava are interposed which have flowed down the outward conical sides of the mountain. (Fig. 43. is an ideal section of Vesuvius and Somma through the axis of the cones, showing the manner in which the beds of scoria and of lava lie upon each other, the extremities of which beds are seen edgewise in the cliff at $m m$ and $k k$, fig. 49,43 , and 44 ).

This assemblage of scoria and lava is traversed abruptly and vertically by streams of solid lava $(n n$, fig. 44$)$, reaching from 
from top to bottom of the cliff. These last I conceive to have flowed in rents of the antient mountain, which rents had acted as pipes through which-the lavas of the lateral eruptions were conveyed to the open air. This scene presents to the view of an attentive observer a real specimen of those internal streams which we have just been considering in speculation, and they may exhibit circumstances decisive of the opinions here advanced. For, if one of these streams had formerly been connected with a lateral eruption discharged at more than 600 feet above the Atrio del Cavallo, it might possibly contain the carbonate of lime. But could we suppose that depth to extend to 1708 feet, the interference of air-bubbles, and the action of a stronger heat than was merely required for the fusion of the carbonate, might have been overcome.

Perhaps the height of Vesuvius has never been great enough for this purpose. But could we suppose $Æ$ tna to be cleft in two, and its structure displayed, as that of Vesuvius has just been described, there can be no doubt that internal streams of lava would be laid open, in which the pressure must have far exceeded the force required to constrain the carbonic acid of limestone, since that mountain occasionally delivers lavas from its summit, placed 10.954 feet above the level of the Mediterranean*, which washes its base. I recollect having seen, in some parts of Ætna, vast chasms and crags, formed by volcanic revolutions, in which vertical streamś of lava, similar to those of Somma, were apparent. But my attention not having been turned to that object till many years afterwards, I have only now to recommend the investigation of this interesting point to future travellers.

What has been said of the heat conveyed by internal volcanic streams, applies equally to that deeper and more general heat by which the lavas themselves are melted and propelled upwards. That they have been really so propelled, from a great internal mass of matter, in liquid fusion, seems to admit of no doubt, to whatever cause we ascribe the heat

* Philosophical Transactions 1777 , p. 595. 
of volcanoes. It is no less obvious, that the temperature of that liquid must be of far greater intensity than the lavas, flowing from it, can retain when they reach the surface. Independently of any actual eruption, the body of heat contained in this vast mass of liquid must diffuse itself through the surrounding substances, the intensity of the heat being diminished by slow gradations, in proportion to the distance to which it penetrates. When, by means of this progressive diffusion, the beat has reached an assemblage of loose marine deposites, subject to the pressure of a great superincumbent weight, the whole must be agglutinated into a mass, the solidity of which will vary with the chemical composition of the substance, and with the degree of heat to which each particular spot has thus been exposed. At the same time, analogy leads us to suppose that this deep and extensive heat must be subject to vicissitudes and intermissions like the external phænomena of volcanoes. We have endeavoured to explain some of these irregularities, and a similar reasoning may be extended to the present case. Having shown that small internal streams of lava tend successively to pervade every weak part of a volcanic mountain, we are led to conceive that the great masses of heated matter just mentioned will be successively directed to different parts of the earth ; so that every loose assemblage of matter lying in a submarine and subterranean situation, will, in its turn, be affected by the indurating cause, and the influence of internal volcanic heat will thus be circumscribed within no limits but those of the globe itself.

A series of undoubted facts prove that all our strata once lay in a situation similar in all respects to that in which the marine deposites just mentioned have been supposed to lie.

The inhabitant of an unbroken plain, or of a country formed of horizontal strata, whose observations have been confined to his native spot, can form no idea of those truths which at every step, in an alpine district, force themselves on the mind of a geological observer. Unfortunately for the progress of geology, both London and Paris are placed in countries of little interest; and those scenes by which the principles of this science are brought into view in the most 
striking manner, are unknown to many persons best capable of appreciating their value. The most important, and at the same time the most astonishing truth which we learn by any geological observations, is, that rocks and mountains now placed at an elevation of more than two miles above the level of the sea, must at one period have lain at its bottom. This is undoubtedly true of those strata of limestone which contain shells; and the same conclusion must be extended to the circumjacent strata. The imagination struggles against the admission of so violent a position, but must yield to the force of unquestionable evidence; and it is proved by the example of the most eminent and cautious observers, that the conclusion is inevitable*.

Another question here occurs, which has been well treated by Mr. Playfair. Has the sea retreated from the mountains? or have they risen out of the sea? He has shown that the balance of probability is incomparably in favour of the latter supposition; since, in order to maintain the former, we must dispose of an enormous mass of sea, whose depth is several miles, and whose base is greater than the surface of the whole sea. Whereas the elevation of a continent out of a sea like ours, would not change its level above a few feet; and even were a great derangement thus occasioned, the water would easily find its level without the assistance of any extraordinary supposition. The elevation of the land, too, is evinced by what has occasionally happened in volcanic regions, and affords a complete solution of the contortion and erection of strata, which are almost universally admitted to have once lain in a plane and horizontal position.

Whatever opinion be adopted as to the mode in which the land and the water have been separated, no one doubts of the antient submarine situation of the strata.

An important series of facts proves that they were likewise subterranean. Every thing indicates that a great quantity of matter has been removed from what now constitutes the surface of our globe, and enormous deposites of loose

* Saussure, Voyages dans les Alpes, tom. ii. p. 99-104.

fragments, 


\section{Effects of Heat modified by Compression.}

fragments, evidently detached from masses similar to our common rock, evince the action of some very powerful agent of destruction. Analogy, too, leads us to believe that all the primary rocks have once been covered with secondary; yet in vast districts no secondary rock appears. In short, geologists seem to agree in admitting the general position, that very great changes of this kind have taken place in the salid surface of the globe, however much they may differ as to their amount, and as to their causes.

Dr. Hutton ascribed these changes to the action, during very long time, of those agents, which at this day continue slowly to corrode the surface of the earth; frosts, rains, the ordinary floods of rivers, \&c., which he conceives to have acted always with the same force, and no more. But to this opinion I could never subscribe, having early adopted that of Saussure, in which he is joined by many of the continental geologists. My conviction was founded upon the inspection of those facts in the neighbourhood of Geneva, which he has adduced in support of his opinion. I was then convinced, and I still believe, that vast torrents, of depth sufficient to overtop our mountains, have swept along the surface of the carth, excavating valleys, undermining mountains, and carrying away whatever was unable to resist such powerful corrosion. If such agents have been at work in the Alps, it is difficult to conceive that our countries should bave been spared. I made it therefore my business to search for traces of similar operations here. I was not long in discovering such in great abundarice; and, with the help of several of my friends, I have traced the indications of vast torrents in this neighbourhood as obvious as those I for merly saw on Saleve and Jura. Since I announced my opinion on this subject, in a note subjoined to my paper on whinstone and lava, published in the fifth volume of the Transactions of this Society, I have met with many confirmations of these views. The most important of these are derived from the testimony of my friend lord Selkirk, who has lately met with a series of similar facts in North America.

It would be difficult to compute the effects of such an agent; but if, by means of it, or of any other cause, the whole 
whole mass of secondary strata, in great tracts of country, has been removed from above the primary, the weight of that mass alone must have been sufficient to fulfil all the conditions of the Huttonian theory, without having recourse to the pressure of the sea. But when the two pressures were combined, how great must have been their united strength!

We are authorised to suppose that the materials of our strata, in this situation, underwent the action of fire. For volcanoes have burnt long before the earliest times recorded in history, as appears by the magnitude of some volcanic mountains; and it can scarcely be doubted that their fire has acted, without any material cessation, ever since the surface of our globe acquired its present form. In extending that same influence to periods of still higher antiquity, when our strata lay at the bottom of the sca, we do no more than ascribe permanence to the existing laws of nature.

The combination of heat and compression resulting from these circumstances, carries us to the full extent of the Huttonian theory, and enablcs us, upon its principles, to account for the igneous formation of all rocks from loose marine deposites.

The sand would thus be changed to sandstone, the shells to limestone, and the animal and vegetable substances to coal.

Other beds, consisting of a mixture of various substances, would be still more affected by the same heat. Such as contained iron, carbonate of lime, and alkali, together with a mixture of various earths, would enter into thin fusion, and, penetrating through every crevice that occurred, would, in some cases, reach what was then the surface of the earth, and constitute lava: in other cases it would congeal in the internal rents, and constitute porphyry, basalt, greenstone, or any other of that numerous class of substances which we comprehend under the name of whinstone. At the same time, beds of similar quality, but of composition somewhat less fusible, would enter into a state of viscidity, such as many bodies pass through in their progress towards fusion. In this state, the particles, though far from possessing the same freedom as in a liquid, are susceptible of crystalline arrangement ; 
arrangement*; and the substance, which, in this sluggish state, would be little disposed to move, being confined in its original situation by contiguous beds of more refractory matter, would crystallize without undergoing any change of place, and constitute one of those beds of whinstone which frequently occur interstratified with sandstone and limestone.

In other cases, where the heat was more intense, the beds of sand, approaching more nearly to a state of fusion, would acquire such tenacity and toughness, as to allow themselves to be bent and contorted, without laceration or fracture, by the influence of local motions, and might assume the shape and character of primary sehistus ; the limestone would be highly crystallized, and would become marble, or, entering into thin fusion, would penetrate the minutest rents in the form of calcareous spar. Lastly, when the heat was higher still, the sand itself would be entirely melted, and might be converted, by the subsequent effects of slow cooling, into granite, sienite, \&c.; in some cases, retaining traces of its original stratification, and constituting gneiss and stratified granite; in others, flowing into the crevices, and forming veins of perfect granite.

In consequence of the action of beat upon so great a quantity of matter, thus brought into a fluid or semifluid state, and in which, notwithstanding the great pressure, some substances would be volatilized, a powerful heaving of the superincumbent mass must have taken place, which, by re-

- This state of viscidity, with its numberless modifications, is deserving of great attention, since it affords a solution of some of the most important geological questions. The mechanical power exerted by some substances in the act of assuming a crystalline form, is well known. I have seen a set of large and broad crystals of ice, like the blade of a knife, formed in a mass of clay of such stiffiress that it had just been used to make cups for chemical putposes. In many of my former experiments I found that a fragment of glass, made from whinstone or lava, when placed in a muffle heated to the melting point of silver, assumed a crystalline arrangement, and underwent a complete change of character. During this change it became soft, so as to yield to the touch of an iron rod; yet retained such stiffness, that, lying untouched in the muffle, it preserved its shape entirely, the sharp angles of its fracture not being in the least blunted. 
peated efforts, succeeding each other from below, would at last elevate the strata into their present situation.

The Huttonian theory embraces so wide a field, and comprehends the laws of so many powerful agents exerting their influence in circumstances and in combinations hitherto untried, that many of its branches must still remain in an unfinished state, and may long be exposed to partial and plausible objections, after we are satisfied with regard to its fundamental doctrines. In the mean time I trust that the object of our pursuit has been accomplished, in a satisfactory manner, by the fusion of limestone under pressure. This single result affords, I conceive, a strong presumption in favour of the solution which Dr. Hutton has advanced of all the geological phænomena; for the truth of the most doubtful principle which he has assumed, has thus been established by direct experiment.

\section{A PPENDIX.}

No. I.

\section{Specific Gravity of some of the foregoing Results.}

As many of the artificial limestones and marbles produced in these experiments were possessed of great hardness and compactness, and as they had visibly undergone a great diminution of bulk, and felt heavy in the hand, it seemed to me an object of some consequence to ascertain their specific gravity, compared with each other, and with the original substances from which they were formed. As the original was commonly a mass of chalk in the lump, which, on being plunged into water, begins to absorb it rapidly, and continues to do so during a long time, so as to vary the weight at every instant, it was impossible, till the absorption was complete, to obtain any certain result; and to allow for the weight thus gained, required the application of a method different from that usually employed in estimating specific gravity.

$$
\text { Vol. 25. No. 99. Aug. } 1806 .
$$


In the common method, the substance is first weighed in air, and then in water; the difference indicating the weight of water displaced, and being considered as that of a quantity of water equal in bulk to the solid body. But as chalk, when saturated with water, is heavier, by about one-fourth, than when dry, it is evident that its apparent weight in water must be increased, and the apparent loss of weight diminished exactly to that amount. To have a just estimate, then, of the quantity of water displaced by the solid body, the apparent loss of weight must be increased by adding the absorption to it.

Two distinct methods of taking specific gravity thus present themselves, which it is of importance to keep separate, as each of them is applicable to a particular class of subjects.'

One of these methods consists in comparing a cubic inch of a substance in its dry, state, allowing its pores to bave their share in constituting its bulk, with a cubic inch of water.

The other depends upon comparing a cubic inch of the solid matter of which the substance is composed, independently of vacuities, and supposing the whole reduced to perfect solidity, with a cubic inch of water.

Thus, were an architect to compute the efficacy of a given bulk of earth, intended to load an abutment, which earth was dry, and should always remain so, he would undoubtedly follow the first of these modes : whereas, were a farmer to compare the specific gravity of the same earth with that of any other soil, in an agricultural point of view, he would use the second mode, which is involved in that laid down by Mr. Davy.

As our object is to compare the specific density of these results, and to ascertain to what amount the particles have approached each other, it seems quite evident that the first mode is suited to our purpose. This will appear most distinctly by inspection of the following table, which has been constructed so as to include both. 
Talle of Specific Gravities.

\begin{tabular}{|c|c|c|c|c|c|c|c|c|c|}
\hline I. & $\begin{array}{c}\text { II. } \\
\text { Weight in } \\
\text { Air, dry. }\end{array}$ & $\begin{array}{c}\text { III. } \\
\text { weight in } \\
\text { Wuter. }\end{array}$ & $\begin{array}{c}\text { IV. } \\
\text { Weight in } \\
\text { Air, wer. }\end{array}$ & 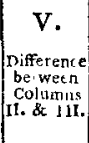 & 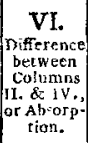 & $\begin{array}{c}\text { VII. } \\
\text { Absorp- } \\
\text { tion per } \\
\text { cent. }\end{array}$ & $\begin{array}{c}\text { VIII. } \\
\text { sum of } \\
\text { colyonss } \\
\text { v. \& VI. }\end{array}$ & $\begin{array}{l}\text { IX. } \\
\text { Specific } \\
\text { Gravity } \\
\text { by con- } \\
\text { mon Mode }\end{array}$ & $\begin{array}{l}\mathbf{X} . \\
\text { Specific } \\
\text { Gr avity } \\
\text { by new } \\
\text { Mode. }\end{array}$ \\
\hline 1. & $12.5 \cdot 90$ & 77.55 & 185.65 & $47 \cdot 35$ & $9 \cdot 75$ & $7 \cdot 74$ & $57 \cdot 10$ & $2 \cdot 604$ & $2 \cdot 204$ \\
\hline 2. & $\begin{array}{r}994 \\
\end{array}$ & 6.18 & $\begin{array}{r}0 \cdot 99 \\
\end{array}$ & 3.81 & & 0.50 & 386 & $2 \cdot 609$ & 2.575 \\
\hline 3. & 15.98 & 9.70 & 1602 & 6.28 & 0.04 & 0.25 & 6.32 & $2 \cdot 544$ & 2.528 \\
\hline 4. & $5 \cdot 47$ & 3.33 & $5 \cdot 48$ & $2 \cdot 14$ & 0.01 & 0.18 & $2 \cdot 15$ & 2.556 & 2.544 \\
\hline 5. & $18 \cdot 04$ & $10 \cdot 14$ & 18.06 & $7 \cdot 90$ & 0.02 & 0.11 & $7 \cdot 92$ & 2.283 & $2 \cdot 277$ \\
\hline 6. & $6^{\circ} 48$ & 3.74 & $7 \cdot 10$ & $2 \cdot 74$ & 0.62 & $9 \cdot 56$ & 336 & $2-365$ & 1.928 \\
\hline 7. & 10.32 & $5 \cdot 97$ & $10 \cdot 36$ & 4.35 & 0.04 & 0.39 & $4: 39$ & 2.572 & 2.350 \\
\hline 8. & $54 \cdot 57$ & 31.90 & $55 \cdot 23$ & $28 \cdot 27$ & 0.66 & $1 \cdot 21$ & $28 \cdot 93$ & $2 \cdot 345$ & $2 \cdot 280$ \\
\hline 9. & $72 \cdot 27$ & $41 \cdot 10$ & $76 \cdot 13$ & $31 \cdot 17$ & 3.86 & $5 \cdot 34$ & 35.03 & $2 \cdot 318$ & $2 \cdot 069$ \\
\hline 10. & $37 \cdot 75$ & $21 \cdot 15$ & 38.30 & 16.60 & 0.55 & $1 \cdot 45$ & $17 \cdot 15$ & $2 \cdot 274$ & $2 \cdot 201$ \\
\hline 11. & 21.21 & $12 \cdot 55$ & 21.26 & $8 \cdot 66$ & 0.05 & 0.24 & 8.71 & $2 \cdot 449$ & $2 \cdot 435$ \\
\hline $\left.\begin{array}{c}12 . \\
\text { Marble. }\end{array}\right\}$ & 18.59 & $11 \cdot 56$ & $18 \cdot 61$ & 7.03 & 0.02 & 0.18 & 7.05 & $2 \cdot 644$ & $2 \cdot 696$ \\
\hline $\left.\begin{array}{c}\text { I3. } \\
\text { Chalk. }\end{array}\right\}$ & $504 \cdot 15$ & $302-40$ & 623.20 & $201 \cdot 75$ & $119 \cdot 05$ & $23 \cdot 61$ & $320 \cdot 80$ & $2 \cdot 498$ & 1.571 \\
\hline $\left.\begin{array}{c}14 . \\
\text { Average } \\
\text { Chalk. }\end{array}\right\}$ & 444.30 & 264.35 & 550.80 & $179 \cdot 95$ & 106.50 & 23.97 & 286.45 & $2 \cdot 469$ & 1.551 \\
\hline $\left.\begin{array}{c}15 . \\
\text { Rammed } \\
\text { Powder. }\end{array}\right\}$ & 283.97 & - & - & - & - & - & $198 \cdot 65$ & - & 1.429 \\
\hline
\end{tabular}

\section{Explanation.}

Column I. contains the number affixed to each of the specimens whose properties are expressed in the table.

The first eleven are the same with those used in the paper read in this society on the 30th of August 1804, and published in Nicholson's Journal for October following, and which refer to the same specimens. No. 12. is a specimen of yellow marble, bearing a strong resemblance to No. 3 . No. 13. a specimen of chalk. No. 14. shows the average of three trials with chalk. No. 15. some pounded chalk, rammed in the manner followed in these experiments. In order to ascertain its specific gravity, I rammed the powder into a glass tube, previously weighed; then, after weighing the whole, I removed the chalk, and filled the same tube 
with water. I thus ascertained, in a direct manner, the weight of the substance, as stated in Column II., and that of an equal bulk of water, stated in Column VIII.

Column IT. Weight of the substance, dry in air, after exposure, during several hours, to a heat of $212^{\circ}$ of Fahrenheit.

Column III. Its weight in water, after lying long in the liquid, so as to perform its full absorption; and all air-bubbles being carefully removed.

Column IV. Weight in air, wet. The loose external moisture being removed by the touch of a dry cloth, but no time being allowed for evaporation.

Column V. Difference between Columns II. and III., or apparent weight of water displaced.

Column VI. Difference between Columns II. and IV., or the absorption.

Column VII. Absorption reduced to a per centage of the dry substance.

Column VIII. Sum of Culumns V. and VI., or the real weight of water displaced by the body.

Column IX. Specific gravity, by the common mode, resulting from the division of Column II. by Column V.

Column X. Specific gravity, in the new mode, resulting from the division of Column II. by Column VIII.

The specific gravities ascertained by the new mode, and expressed in Column X. correspond very well to the idea which is forned of their comparative densities, from other circumstances, their hardness, compact appearance, susceptibility of polish, and weight in the hand.

The case is widely different when we attend to the results of the common method contained in Column IX. Here the specific gravity of chalk is rated at $2 \cdot 498$, which exceeds considerably that of a majority of the results tried. Thus, it would appear, by this method, that chalk has become lighter by the experiment, in defiance of our senses, which evince an increase of density.

This singular result arises, I conceive, from this ; that, in our specimens, the faculty of absorption has been much more decreased than the porosity. Thus, if a piece of crude chalk, 
chalk, whose specific gravity had previously been ascertained by the common mode, and then well dried in a heat of $212^{\circ}$, were dipped in varnish, which would penetrate a little way into its surface; and, the varnish having hardened, the chalk were weighed in water, it is evident that the apparent loss of weight would now be greater by 23.61 per cent. of the dry weight than it had been when the unvarnished chalk was weighed in water; because the varnish, closing the superficial pores, would quite prevent the absorption, while it added but little to the weight of the mass, and made no change on the bulk. In computing, then, the specific gravity by means of this last result, the chalk would appear very much lighter than at first, though its density had, in fact, been increased by means of the varnish.

A similar effect seems to have been produced in some of these results by the agglutination or partial fusion of part of the substance, by which some of the pores have been shut out from the water.

This view derives some confirmation from an inspection of Columns VI. and VII.; the first of which expresses the absorption; and the second, that result reduced to a per centage of the original weight. It there appears, that whereas chalk absorbs 23.97 per cent., some of our results absorb only 0.5 , or so low as 0.11 per cent. So that the power of absorption has been reduced from about one-fourth to less than the five hundredth of the weight.

I have measured the diminution of bulk in many cases, particularly in that of No. 11. The chalk, when crude, ran to the 75 th degree of Wedgewood's gage, and shrunk so much during the experiment, that it ran to the $161 \mathrm{st}$; the difference amounting to 86 degrces. Now, I find that Wedgewood's gage tapers in breadth from 0.5 at zero of the scale, to 0.3 at the 240 th degree. Hence we have for one degree 0.000833 . Consequently, the width, at the 75 th degree, amounts to 0.437525 ; and at the $161 \mathrm{st}$, to 0.365887 . These numbers, denoting the linear measure of the crude chalk, and of its resuit under heat and compression, are as 100 to 83.8 ; or, in solid bulk, as 100 to 57.5 . Computing the densities from this source, they are as 3 to 1.73 . The speO 3 cific 
cific gravities in the table, of the chalk, and of this result, are as $1.551: 2.435$; that is, as 1 to 1.57 . These conclusions do not correspond very exactly; but the chalk employed in this experiment was not one of those employed in determining average specific gravity in the table; and other circumstances may have contributed to produce irregularity. Comparing this chalk with result second, we have 1.551 : $2 \cdot 575$, so $1: 1 \cdot 6602$.

No. II.

Talle containinig the Reduction of the Forces mentioned in Chap. VII. to a common Siandard.

\begin{tabular}{|c|c|c|c|c|c|c|}
\hline $\begin{array}{c}\text { I. } \\
\text { Number of } \\
\text { Experiment } \\
\text { referred to } \\
\text { in Chap. VII. }\end{array}$ & $\begin{array}{c}\text { I1. } \\
\text { Bore, in } \\
\text { Decimals } \\
\text { of an } \\
\text { Inch. }\end{array}$ & $\begin{array}{c}\text { III. } \\
\text { Pressure } \\
\text { in Hun- } \\
\text { dred } \\
\text { Weights. }\end{array}$ & $\begin{array}{l}\text { IV. } \\
\text { 'Tempe- } \\
\text { rature by } \\
\text { Wedge- } \\
\text { wood's } \\
\text { Pyrom. }\end{array}$ & $\begin{array}{c}\text { V. } \\
\text { Depth of } \\
\text { Sea in Feet. }\end{array}$ & $\begin{array}{l}\text { VI. } \\
\text { Ditto in } \\
\text { Miles. }\end{array}$ & $\begin{array}{c}\text { VII. } \\
\text { Pressure, } \\
\text { expressed } \\
\text { in Atmo- } \\
\text { spheres. }\end{array}$ \\
\hline 1 & 0.75 & 3 & 22 & 1708.05 & 0.3235 & $51 \cdot 87$ \\
\hline $2^{\prime}$ & 0.75 & 3 & 25 & 1708.05 & 0.3235 & $51 \cdot 87$ \\
\hline 3 & $0 \cdot 75$ & 10 & 20 & $5693 \cdot 52$ & $1 \cdot 0783$ & $172 \cdot 92$ \\
\hline 4 & 0.75 & 10 & 31 & $5693 \cdot 52$ & 1.0783 & 172.92 \\
\hline 5 & 0.75 & 10 & 41 & $5693 \cdot 52$ & $1 \cdot 0783$ & $172 \cdot 92$ \\
\hline 6 & 0.75 & 10 & 51 & 5693.52 & 1.0783 & $172 \cdot 92$ \\
\hline 7 & $0 \cdot 75$ & 10 & - & $5693 \cdot 52$ & 1.0783 & $172 \cdot 92$ \\
\hline 8 & 0.54 & $\mathcal{2}$ & - & 2196.57 & 0.4160 & 66.71 \\
\hline & & 4 & - & $4393 \cdot 14$ & 0.8320 & $333 \cdot 43$ \\
\hline 9 & 0.5 & 0,1 & & $8896^{*} 12$ & $1 \cdot 6848$ & $270 \cdot 19$ \\
\hline 10 & 0.75 & 3 & 21 & 1708.05 & 0.3235 & 51.87 \\
\hline 11 & $0 \cdot 75$ & 4 & 25 & $2277 \cdot 41$ & 0.4313 & $69 \cdot 70$ \\
\hline 12 & 0.75 & 5 & - & $2846 \cdot 76$ & $0 \cdot 5396$ & $86 \cdot 46$ \\
\hline
\end{tabular}

Explanation.

Column I. contains the number of the experiment, as referred to in the text. Column II. The bore of the barrel used, in decimals of an inch. Column III. The absolute force applied to the barrel, in hundred weights. Column IV. The temperature in Wedgewood's scale. Column V. The depth of sea at which a force of compression would be exerted equal to that sustained by the carbonate in each experiment, expressed in feet, Column VI, The same in miles. 
miles. Column VII. Compressing force, expressed in atmospheres.

Both tables were computed separately, by a friend, Mr. J. Jardine, and myself.

The following data were employed:

Area of a circle of which the diameter is unity, 0.785398 . Weight of a cubic foot of distilled water, according to professor Robison, 998.74 ounces avoirdupois.

Mean specific gravity of sea water, according to Bladh, $1 \cdot 0272$.

Mean height of the barometer at the level of the sea 29.91196 English inches, according to Laplace.

Specific gravity of mercury, according to Cavendish and Brisson, 13.568.

XXXIII. Catalogue of Specimens, showing the Result of Sir JaMEs Halu's Experiments on the Effects of Heat modified by Compression; which were deposited by Sir James HaLl in the British Museum on the 28th of June 1806.

$\mathrm{N}$ Numbers 1, 2, 3, 4, 5, 6, and 7 , were all produced, in separate experiments, from pounded carbonate of lime. No. 1. was obtained in 1799. It is a firm stone, requiring a smart blow of a hammer to break it. It was enclosed in a cartridge of paper, the mark of which it still bears. The other six are still harder, and more compact, approaching nearly in these qualities to common limestone.

Nos. 2, 4, and 7, possess a degree of semi-transparency most remarkable in No. 4; and all of these specimens exhibit an uneven fracture, approaching to that of bees' wax and marble. Their colours are variously, though slightly, tinged with yellow and blue; in particular No. 3, which, though produced from common white chalk, resembles a yellow marble.

Nos. 3, 5, and 6, have taken a tolerable polish. No. 7 . contains a shell introduced along with the pounded chalk, and now closely incorporated with it.

$\mathrm{O} 4$

Along 